\title{
OCCUPATIONAL HEALTH AND SAFETY POLICY IN THE OPERATIONS OF THE WOOD PROCESSING INDUSTRY IN KUMASI, GHANA
}

\author{
D. Adei and E. Y Kunfaa \\ Department of Planning. \\ Kwame Nkrumah University of Science and Technology, Kumasi, Ghana
}

\begin{abstract}
The operations of the Wood Processing Industry (WPI) are generally associated with high levels of occupational hazards with consequent health risks. The purpose of this study was to assess the perceived occupational health hazards exposure and the effectiveness of the policies put in place to ensure the health and safety of workers in 14 randomly selected WPIs located at Ahensan, Asokwa and Kaasi industrial area in Kumasi. Primary data on occupational hazards and policies were obtained from the WPIs through observation, semi-structured interviews, individually administered questionnaires while secondary data on industrial accidents was obtained from Kumasi Metropolitan Labour Department (KMLD) and Department of Factories Inspectorate (DFI) for Ghana for the analysis. The study found the trend in perception of unsafe working environment increasing with decreasing size of companies. The WPI surveyed revealed vulnerability of the workers to occupational hazards and accidents as a result of inadequate engineering and administrative controls, and the low use of personal protective equipment. The lack of commitment by management to implement OSH policy where it existed, consideration of payment of insurance premium as sufficient protection for their workers, restrictive inspections, education and enforcement by under resourced DFI (which shows extent of government commitment to OSH) and Timber and Wood Workers union inability to project OSH agenda have contributed substantially to WPI's neglect of workers health and safety. It appeared that statistics at the Labour Departments in Ghana will make a better case for OSH than the under estimated DFI figures which have been used extensively and consistently in the past, because workmen's compensation provides an incentive for higher notification of industrial accident at the Labour Department.
\end{abstract}

Keywords: Occupational health and safety, Occupational hazards, Occupational Accidents, Safety Policy, Wood Processing Industry 


\section{INTRODUCTION}

The working capacity of the workforce sustains the economic and material base of society. Thus occupational health and well being of working people are crucial pre-requisites for productivity and are of utmost importance for all socioeconomic and sustainable development (WHO, 1994). In the absence of a national occupational safety and health policy in Ghana, the Factories, Offices and Shops Act of 1970, Workmen's Compensation Law Act 187 (1987), and Labour Act 651 (2003) are the main legislative documents on occupational safety and health in Ghana. Despite these legal framework, related accidents, injuries and diseases cost Ghana about 7 percent of GDP (Ghana News Agency, 2003).

Wood products contribute about 11 percent of Ghana's foreign exchange earnings, employ over 100,000 workers and provide a livelihood for over 2.5 million Ghanaians (Acquah-Moses, 2002). Despite this contribution to the economy, the operations of the WPIs are generally associated with high levels of occupational hazards with consequent risk to health. Records at the Department of Factories Inspectorate from 19871998 indicate that about 50 percent of the fatal accidents in the industrial sector came from the wood working sector in Ghana (Boateng and Nimako, 2000; MOH/GHS, 2002).

The objectives of this study therefore, were to: assess occupational health hazards that wood workers are exposed to; investigate if Wood Processing Companies in the study area have Occupational Health and Safety Policy and the extent to which they have operationalized it; and assess the extent of enforcement of OSH legislations. The outcome of this study would sensitize both government and the WPIs on the extent to which occupational health problems impact on socio-economic development, to give $\mathrm{OSH}$ a serious consideration.

\section{MATERIALS AND METHODS}

The research approach was cross sectional and specifically case study design was used.
The study, which was, carried out from January to June 2005, focused on fourteen WPIs at Ahensan, Asokwa and Kaasi industrial areas in $\mathrm{Ku}-$ masi, Ashanti Region, Ghana. The research was mainly based on primary and secondary sources of data collection; the primary data, which included OSH hazards and policy, were obtained through observation, semi-structured interviews and individually administered questionnaire whilst the secondary data on industrial accidents were obtained from Kumasi Metropolitan Labour Department (KMLD) and the Department of Factories Inspectorate (DFI) for Ghana. A combination of purposive, proportional stratification and quota sampling techniques were used for this research. A sampling frame of Wood Processing Industries in Kumasi was obtained from the Timber Industries Development Division. Using the mathematical approach: $\mathrm{n}=\mathrm{N} /\left[1+\mathrm{N}(\alpha)^{2}\right]$ (where $\mathrm{n}=$ sample; $\mathrm{N}=$ sample frame; $\alpha=$ confidence level), a sample size of 26 was obtained from the sampling frame of (i.e. total number of WPI in Kumasi, N) 35 at a confidence level $(\alpha)$ of $90 \%$ (sample size $\left.n=35 / 1+35(0.1)^{2}=26\right)$. The WPIs were stratified according to their locations at Ahensan, Asokwa and Kaasi. In each stratum, the WPIs were grouped into large, medium and small scale and the proportional stratified sampling technique was used to select the total number of WPI in each location. Despite the reassurance that the study had no legal, political or economic undertones, the response rate was 70 percent. Thus the total number of WPIs actually surveyed in the study area was 14 , comprising of 3 large, 7 medium, and 4 small scale industries. In the large WPIs questionnaires were administered to 30 workers, 10 in the medium and five in the small scale WPIs. For effective representation the workers were stratified into labourers, operators, technicians, drivers/mate and administrators. Quota sampling was used to administer the questionnaires, after pre-testing the questionnaire. One hundred and eighty workers and 31 managers and supervisors were administered with questionnaires; the total sampling size used was 211 .

162 Journal of Science and Technology, Volume 27 no. 2, August, 2007 
The workers who participated in the study were predominately male (96.7 percent), and the largest proportions (40.6 percent) of the workers were aged between 31 and 40, while 30 percent were between 41 and 50 years. They were generally educated, 37.8 percent had MSLC, 23.9 percent had SSS/GCE “O” level, 16.1 percent had Technical/Vocational education and only 7.8 percent had not had any formal education.

Purposive sampling technique was used to interview heads of department of Factories Inspectorate, Department of Labour, OSH section of the Ministry of Health, Timber Industries Development Division, Environmental Protection Agency, State Insurance Company, Trade Union Congress and Ghana Timber and Wood Workers Association. The questionnaires were analyzed using the Statistical Package for Social Science (SPSS) software (SPSS- PC for windows, version 11.0). Descriptive analysis was used for the observation and interviews conducted.

\section{RESULTS AND DISCUSSION}

\section{Occupational Hazard Exposure}

The survey revealed that employees in the wood processing industry in the study area were exposed to physical, ergonomic, mechanical and chemical hazards.

The perceived physical hazards in the study were sawdust, noise and extreme hot temperature. Sawdust was a major hazard in all the Wood Processing companies surveyed which is consistent with the work place health and safety hazards survey by the MOH (1998), that showed that wood dust and shavings were major hazards among woodworkers. The percentage of workers who were provided with nose masks and those who claimed to use it may be an over estimation (Table 1). Apart from one small company surveyed, where all workers were seen wearing their nose masks, some workers in the rest of the companies surveyed had their nose masks on their foreheads because they found them uncomfortable to use. All the three large companies and five out of the seven medium sized companies had sawdust extractors. However, 53.0 percent and 41.4 percent of the workers in the large and medium sized companies respectively perceived the sawdust extractor as inefficient because some amount of sawdust was left in the air. All the small sized companies had no sawdust extractors, exposing the workers to wood dust inhalation and body exposure. Matooane (1997) in his study of ten wood working industries in Lesotho made similar observations. Ear and eye infections, skin rashes and difficulty in breathing experienced by some of the workers agrees with Bean and Butcher's (2006) findings on the health effects of wood dust exposure hazards.

Efforts made at managing noise levels were mainly in the provision of earmuffs and regular maintenance of equipment. Provision of ear protectors was mainly restricted to machine operators. Majority of the workers in the large, medium, and small WPI's perceived noise exposure to be of no effect on hearing (Table 1). Amedofu (2002) observed that hearing impairment usually develops slowly over a long time and the impairment can reach the handicapping stage before an individual becomes aware of what has happened. The researcher had to shout when administering the questionnaire to some of the workers at their administration block, which were insulated from noise. This suggests that majority of workers were not aware of their hearing impairment. It therefore appears that where earmuffs were provided their use was not clearly understood.

Both supervisors and workers in the wood processing companies surveyed perceived noise as an inevitable part of the production process. The supervisors had no idea of the quantitative noise levels the workers were exposed to and only 6.5 percent knew that the maximum allowable noise limit for eight hour shift should not be more than 85dBA according to Environmental Protection Agency (EPA) Ghana. Amedofo and AsamoahBoateng (2003) showed that workers in sawmills, and corn mills were exposed to noise levels exceeding $85 \mathrm{dBA}$. 
Workers at the boiler and kiln dryer sections in the large and medium sized companies perceived their work environment to be hot. Workers at the boiler sections experienced profuse sweating although no temperature-monitoring equipment was in place. The companies with clinics (three large and one medium-sized wood processing companies) had on record, complaints of fatigue, discomfort and heat exhaustion as a result of the excessive heat exposure. Ezeonu (2004), reported heat exhaustion caused by exposure to high temperature among kiln workers in a Nigerian company.

Mechanical Hazards

About 22 percent of workers in large, 35 percent in medium and 45 percent in small companies were prone to injuries because the machines they operated did not have any safety devices (Table 1). This explains why 18.9 percent of injuries from the survey were due to machine cuts in the large companies, 17.1 percent from medium and 20.1 percent from small companies, which resulted in lacerations, fractures and contusions of fingers, hands and legs.

\section{Ergonomic Hazards}

Occupational exposure to ergonomic hazards at the WPIs was mainly due to lifting of weights and uncomfortable posture during working hours. Some workers had to stand or bend to pick

Table 1: Percentage of different hazard exposures perceived by workers

\begin{tabular}{|c|c|c|c|}
\hline HAZARD EXPOSURE & LARGE(n=90) & MEDIUM (n=70) & SMALL $(n=20)$ \\
\hline \multicolumn{4}{|l|}{ PHYSICAL } \\
\hline Production of sawdust & 34.4 & 48.6 & 60.0 \\
\hline Sawdust extractor & 100 & 71.4 & 0 \\
\hline Efficient extractor & 46.7 & 58.6 & - \\
\hline Inefficient extractor & 53.3 & 41.4 & - \\
\hline Provision of nose mask & $54.8(\mathrm{n}=31)$ & $50.0(\mathrm{n}=34)$ & $33.3(n=12)$ \\
\hline Noise & 90 & 91.4 & 95.0 \\
\hline Effect of noise & $(\mathrm{n}=81)$ & $(n=64)$ & $(n=19)$ \\
\hline Pain in the ear & 42.0 & 36.0 & 26.3 \\
\hline Impaired hearing & 11.0 & 12.5 & 10.5 \\
\hline No effect & 47.0 & 51.5 & 63.2 \\
\hline Provision of ear protectors & 4.9 & 3.1 & 10.5 \\
\hline $\begin{array}{l}\text { MECHANICAL } \\
\text { Operation of machine } \\
\text { Safety Device }\end{array}$ & $62.1(18.9)^{*}$ & $70.0(17.1) *$ & $55.0(20.10) *$ \\
\hline Machine guards & 35.0 & 37.0 & 30.0 \\
\hline Fence around machine & 4.4 & 4.3 & - \\
\hline Machine guards \& fence & 9.0 & 4.3 & - \\
\hline $\begin{array}{l}\text { ERGONOMIC } \\
\text { Lifting of load }\end{array}$ & & & \\
\hline Very heavy & 14.4 & 21.4 & 5.0 \\
\hline Heavy & 35.6 & 35.7 & 50.0 \\
\hline Normal & 50.0 & 42.9 & 45.0 \\
\hline CHEMICAL & 17.8 & 11.4 & 15.0 \\
\hline
\end{tabular}

( )* Occupational injuries due to machine cuts

164 Journal of Science and Technology, Volume 27 no. 2, August, 2007 
up lumber and plywood for more than seven hours during the eight-hour shift. Awkward work postures such as prolonged standing, bending, or kneeling among wood workers in Lesotho led to common complaint of low back pain (Matooane, 1997). It was observed in all the companies that the labourers preferred to pile up more than five or six lumber and plywood together before lifting, making the load heavy. NIOSH guidance on weight lifting gives 55 pounds as a safe level for the average person (Niu, 2000). However, Section 27 of Ghana's Factories, Offices and Shop Act (Act 328) (1970) does not give a maximum permissible lifting weight for workers.

\section{Chemical Hazard Exposure}

The workers were exposed to chemical hazards like gastoxin, glue, sodium chloride, aerolites, cascamite, oxygen, acetylene and gas oil. The exposures to chemical hazards in the large, medium and small WPIs were found to be 17.8, 11.4 and 15.0 percent, respectively (Table 1). These chemicals did not have Material Safety Data Sheet which might raise the workers awareness of safe ways of handling these substances and of procedures to be followed if chemical accident occurred. Even though the workers were provided with rubber gloves and safety boots they perceived it not to be adequate protection from skin rashes, irritation and allergic reaction due to the application of glue. McCann and Babin (2007) recommended good dilution ventilation and additional protective gear such as goggles, and a NIOSH- approved toxic dust mask for factory workers in the chemical industry.

\section{Controlling Occupational Health Hazards and Accident}

Personal Protective Equipment (PPE) was the main measure adopted to mitigate the effect of hazards in all the WPIs. These were safety boots, overall coat, nose masks, ear protectors, goggles and gloves. Generally, apart from the PPE's not being adequate and not properly used, there was lack of enforcement in their use. The supervisors on the factory floor did not also wear PPE. In a study of 120 workplaces in Kenya, Odhiambo (2003) observed that 73 percent of all workplaces had no or insufficient PPE.

There were no safety notices on walls and other vantage points that conveyed instructions/ warning or general information about potential hazards especially in areas where hazard exposure was very high in order to prevent accidents in all the fourteen WPIs.

In this study there appeared to be low administrative and engineering controls in the companies because it appeared most managers perceived injured worker's replacement an easy option, and that insurance cover for injury was a sufficient protection for their workers and companies. Consequently, they perceived occupational hazards in the work place to be normal with their operations and therefore lacked the commitment to ensure safe and healthy practices.

The existing group insurance policy did not have explicit names of workers and this enabled WPI's to get insurance coverage for more workers than they had insured. Records of one insurance company that gave workers group insurance cover (workmen's compensation and payment of medical bills) revealed payment of two or more times injury claims as compared to the premiums paid by some WPI's policy holders. There is no doubt that realistic insurance premium payment by the WPI may raise their safety consciousness and thereby protect the workers. There was also no basis for future litigation on causes of health impairment of workers since none of the companies surveyed performed periodic or exit medical examination. The above factors coupled with restrictive inspections, education and enforcement by under resourced DFI, and lower priority given to $\mathrm{OSH}$ agenda by Timber and Wood Workers Union have contributed substantially to WPI's neglect of workers health and safety. 


\section{WPI's Occupational Health and Safety Policies}

Existences of OSH policy:

Records at the Environmental Protection Agency (EPA) Kumasi office revealed that two large and one medium-sized wood processing companies out of fourteen companies had submitted OSH Policies in May 2004 as part of their Environmental Management Plan (Table 2). The policy statements of these companies were not posted on the notice boards on their company premises neither could they be produced on request. The supervisors and other workers in the three companies with OSH policy were not aware of the existence of the OSH policy. It is difficult to see how a company's OSH policy could be effectively operationalized with general lack of awareness. The two large companies which had OSH policies were operating as freezone companies. For companies operating under free zone, Environmental Management Plan is a requirement. Freezone companies enjoyed incentives such as ten years corporate tax exemption, repatriation of profit and exemption from payment of import duties on imported items among others. Clearly, these incentives served as enough motivation for possession of OSH policy by these companies.

It appeared that Factories Offices and Shop Act 1970, Act 328 guided the managers and supervisors of all the companies. Matooane (1997) showed that of the ten woodworking (four large and six small) industries in Lesotho all the four large companies had OSH policies but only one small company had an OSH policy, indicating little commitment on the part of small companies.

\section{Strategies for Implementation of OSH Policy}

The strategies for implementing OSH policy is discussed based on the harmonized policy and plans in the three WPIs (Table 2) and those without a written OSH policy. The findings are however summarized in Table 3.

\section{Risk Assessment}

Risk assessment was not undertaken at all times to ensure that the existing controls, training and safeguards are still performing their desired function. When performed it was mainly geared towards what was perceived to directly lead to increased productivity, or as a result of investigation of an accident by DFI. Consequently the workers and the employers do not derive the maximum benefit from risk assessment; which is a higher productivity and a healthier working environment and work force.

\section{Creating OSH Awareness}

There was no full time OSH officer employed to ensure the safety and health of workers in all the companies surveyed. All the large and medium sized companies had desk Officers in charge of OSH who had other responsibilities apart from ensuring safety in the work place. Most of them had received on the job training from the DFI. The educational backgrounds of the desk officers in charge of safety were mainly GCE"O" and GCE"A" level holders.

Safety Committee: The three companies who had OSH policy (Table 3) were the only ones that had constituted safety committees made up of managers. Supervisors or unit representatives who could bring their experience to bear on the operations of the committee were not members, neither was there a TUC representative on the committee. This finding is at variance with the study of fifteen Food, Drink and Tobacco (FDT) firms in Ghana, (Boateng, 1997), where 67 percent of the firms surveyed had safety committees, with membership made up of representatives from all departments except one drinking firm whose members were selected on the recommendation of the DFI.

Training, education and information: Training, education and information to a large extent increase worker's productivity. The survey revealed that all the three companies with OSH policies had made some effort to offer training for their workers but this was mainly geared toward meeting production targets. Although some

166 Journal of Science and Technology, Volume 27 no. 2, August, 2007 
Table 2: Harmonized OSH policies/plans in the three wood processing companies.

OSH POLICY: Providing a safe and healthy working environment for employees

GOAL : Prevention of accidents and reduction of health and safety hazards

\begin{tabular}{|c|c|c|}
\hline OBJECTIVES & STRATEGIES & ACTIVITIES \\
\hline 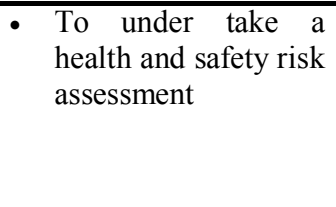 & $\begin{array}{l}\text { - Identify and prevent potential } \\
\text { health hazards in areas that need } \\
\text { attention } \\
\text { Institute regular monitoring and } \\
\text { evaluation of safety performance }\end{array}$ & $\begin{array}{l}\text { - Carry out monthly hazard audit by spotting dangers in the work } \\
\text { area, work method, and the workers. } \\
\text { - Carry out accident investigation } \\
\text { - Provide relevant information on risk assessment to the employees } \\
\text { - Development of the monitoring and evaluation system on safety }\end{array}$ \\
\hline $\begin{array}{l}\text { - To create OSH } \\
\text { awareness }\end{array}$ & $\begin{array}{l}\text { - Appointing a full time health and } \\
\text { safety officer } \\
\text { - Ensure formation of safety com- } \\
\text { mittee } \\
\text { - Provide adequate training and } \\
\text { information on health and safety } \\
\text { - Motivate employees for good } \\
\text { health and safety practices }\end{array}$ & $\begin{array}{l}\text { Employ a full time safety officer } \\
\text { - Form Safety committee } \\
\text { - Disseminate OSH information through news letters, posters and } \\
\text { training programmes in first aid administration, rescue and evacua- } \\
\text { tion in times of emergencies such as fire out break } \\
\text { - Provide incentives to workers who increase their productivity } \\
\text { without accidents } \\
\text { - Provide pre-employment and periodic medical examination }\end{array}$ \\
\hline $\begin{array}{l}\text { - To ensure mainte- } \\
\text { nance of equipments } \\
\text { and machinery }\end{array}$ & $\begin{array}{l}\text { Ensure proper and regular mainte- } \\
\text { nance of machinery and equip- } \\
\text { ments }\end{array}$ & $\begin{array}{l}\text { - Carry out monthly inspections and maintenance of machinery and } \\
\text { plant } \\
\text { - Provide safety guides for machines with dangerous parts. } \\
\text { - Replace worn-out machine parts } \\
\text { - Acquisition of new machines to replace obsolete ones }\end{array}$ \\
\hline $\begin{array}{l}\text { To comply with all } \\
\text { relevant legislation, } \\
\text { regulations and stan- } \\
\text { dards on OSH }\end{array}$ & $\begin{array}{l}\text { - Ensure awareness of the stan- } \\
\text { dards required by all regulatory } \\
\text { agencies } \\
\text { Ensure compliance with the } \\
\text { standard required by all regula- } \\
\text { tory agencies }\end{array}$ & $\begin{array}{l}\text { - Train supervisors on OSH legislation and standards } \\
\text { - Report industrial accidents to appropriate agencies } \\
\text { - Perform environmental monitoring } \\
\text { - Ensure the implementation of recommendations by the department } \\
\text { of Factories Inspectorate, EPA and other regulatory agencies }\end{array}$ \\
\hline $\begin{array}{l}\text { To provide and en- } \\
\text { force use of PPE }\end{array}$ & $\begin{array}{l}\text { - Organize in house training in use } \\
\text { and benefits of PPE }\end{array}$ & $\begin{array}{l}\text { - } \text { Provide the necessary PPE } \\
\text { - Provide appropriate training in the use of PPE } \\
\text { - } \\
\text { Enforce the use of PPE for both workers and supervisors }\end{array}$ \\
\hline
\end{tabular}

Journal of Science and Technology, Volume 27 no. 2, August, 2007 
employees were sent to the Wood Industry Training Centre at Akyawkrom, Kumasi, to attend courses each year, the curriculum of the center did not include OSH. According to an officer from DFI, the department has not been organizing training and education on $\mathrm{OSH}$ for managers, supervisors and employees in the WPI's as it did in the past, because of understaffing and logistical problems. Technical skills and safety training cannot be overemphasized because in a study of the Finnish furniture industry, Gardner et al. (1999) showed that 67 percent of occupational accidents were due to the behaviour of individuals and work place practices. They therefore suggested the need to improve workers' knowledge of the machinery they use and the environment within which they work through proper safety training, to enable them appreciate the dangers associated with negli- gence or carelessness. There were no visible posters on safety in all the companies surveyed and in most cases where they had posters given by the DFI, they were in the drawers of the managers. News letters on safety were non existent in all the fourteen WPI .

Meeting of OSH Standards/ legal requirement The three companies who had OSH policy had installed new machinery in the moulding sections, new kiln dryers and saw dust extractors had been built. The workers in these sections perceived their work environments as safe. The supervisors of all the WPIs surveyed however did not know whether the safety standards for noise, sawdust and temperature among others were met, because they were not monitored and most of the supervisors did not know what the standards were.

Table 3: Summary of findings of WPI with and without OSH policy (percentage)

\begin{tabular}{lcc}
\hline \multicolumn{1}{c}{ WITH OSH POLICY $(\mathrm{n}=3)$} & WITHOUT OSH POLICY $(\mathrm{n}=11)$ \\
\hline Operating under free zone & 66 & 0 \\
Existence of OSH committee & 100 & 0 \\
OSH desk officer & 100 & 64 \\
& & \\
Protection against fire outbreak & 100 & 9 \\
Hydrant & 100 & 100 \\
Fire extinguisher & 100 & 100 \\
Ghana National Fire Service & & \\
& 100 & 9 \\
Provision of Health Service & 100 & 100 \\
Company clinic & 100 & 100 \\
First aid & 100 & 9 \\
Referral & 100 & 9 \\
Keeping of health records & 0 & 0 \\
Medical Examination & & \\
Pre-employment & 100 & 9 \\
Periodic/exit & 0 & 0 \\
Training, education and information & & \\
Formal Training of personal & & \\
Newsletters/posters on OSH & & \\
\hline
\end{tabular}

168 Journal of Science and Technology, Volume 27 no. 2, August, 2007 
Occupational Health Services: The three companies who had OSH policy had their own clinics, which served as a first point for treatment to any employee who was sick or injured before subsequent referral to either the Komfo Anokye Teaching Hospital or Agogo hospital. One large company which did not have OSH policy also had a clinic which provided similar treatment. However, all companies surveyed provided first aid for sick or injured workers before referrals were made. The companies also provided full medical coverage for employees and their dependents. Assessment of clinical records, which were made available (one large and one medium company with OSH policy and one large company without OSH policy), revealed that the most common occupational diseases diagnosed by the doctors were upper respiratory tract infections, musculoskeletal problems (low back pain) conjunctivitis, asthma and hearing problems. These ailments were perceived by the company nurses as being the result of long hours of work in one position, heavy manual lifting, noisy and dusty nature of the work environment. The most common occupational injuries recorded were lacerations, fracture and contusions of fingers, hands and legs.
The three companies who had OSH policy performed pre-employment medical examination, but none of the fourteen companies performed periodic or exit medical examination. Presently because of lack of periodic and exit medical examination establishing an occupational disease is difficult or impossible and therefore compensations are not paid. Medical services provided by all the companies were curative and no emphasis was placed on prevention and health promotion. Again neither do the full time nurses nor the part time doctors pay regular visits to the factory floor. Even though the four companies with clinics had documented workplace injuries, the data had not been collated and scientifically analyzed to establish a correlation between the occupational hazards and the diagnosed diseases, for the benefit of companies.

Reporting Of Occupational Accidents and Injuries: Statistics collected from Department of factories inspectorate (DFI) for Ghana clearly shows under reporting of Industrial accidents as compared to that at the Kumasi Metropolitan Labour Department (KMLD) within Ashanti region (Table 4).

Table 4: Industrial accidents records at DFI and KMLD 1998- 2003

\begin{tabular}{|c|c|c|c|c|c|c|c|c|c|c|c|c|}
\hline \multirow{3}{*}{ Year } & \multicolumn{6}{|c|}{ Industrial Accident Recorded at DFI (Ghana) $^{1}$} & \multicolumn{6}{|c|}{ Industrial Accident Recorded at KMLD ${ }^{2}$} \\
\hline & \multicolumn{3}{|c|}{$\begin{array}{c}\text { No of accidents } \\
\text { notified }\end{array}$} & \multicolumn{3}{|c|}{$\begin{array}{l}\text { No of accident } \\
\text { for WPI }\end{array}$} & \multicolumn{3}{|c|}{$\begin{array}{l}\text { No of injuries } \\
\text { recorded }\end{array}$} & \multicolumn{3}{|c|}{$\begin{array}{c}\text { No of injuries recorded } \\
\text { for WPI }\end{array}$} \\
\hline & $\begin{array}{l}\text { Non } \\
\text { Fatal }\end{array}$ & Fatal & Total & $\begin{array}{l}\text { Non } \\
\text { Fatal }\end{array}$ & Fatal & Total & $\begin{array}{l}\text { Non } \\
\text { Fatal }\end{array}$ & Fatal & Total & $\begin{array}{l}\text { Non } \\
\text { Fatal }\end{array}$ & Fatal & Total \\
\hline 1998 & 175 & 9 & 184 & - & - & - & 256 & 5 & 261 & 154 & 2 & 156 \\
\hline 1999 & 182 & 3 & 185 & 15 & 1 & 16 & 239 & 5 & 244 & 153 & 5 & 158 \\
\hline 2000 & 262 & 8 & 270 & - & - & - & 235 & 9 & 244 & 117 & 4 & 121 \\
\hline 2001 & 201 & 10 & 211 & 35 & 5 & 40 & 216 & 5 & 221 & 144 & 1 & 145 \\
\hline 2002 & 134 & 9 & 143 & - & - & - & 153 & 6 & 159 & 91 & 6 & 97 \\
\hline 2003 & 135 & 2 & 137 & 26 & 0 & 26 & 171 & 5 & 176 & 144 & 1 & 115 \\
\hline Total & 1089 & 41 & 1130 & & & & 1270 & 35 & 1305 & 773 & 19 & 792 \\
\hline Source & $\begin{array}{l}1 \\
2\end{array}$ & $\begin{array}{l}\text { partmer } \\
\text { masi M }\end{array}$ & $\begin{array}{l}\text { of Factc } \\
\text { opolita }\end{array}$ & $\begin{array}{l}\text { es Insp } \\
\text { abour }\end{array}$ & $\begin{array}{l}\text { rate }(D \\
\text { artmen }\end{array}$ & $\begin{array}{l}\text { Ghana } \\
\text { KMLD) }\end{array}$ & shanti & egion & & & & \\
\hline
\end{tabular}


Table 4 and Figure 1 shows that in the six years period from 1998-2003, the total number of industrial accidents recorded at the Kumasi Metro Labour Department (KMLD) within Ashanti Region was 175 cases more than that reported by the Department of Factories Inspectorate (DFI) for the whole country. Analysis of a break down according to industrial classification reported by the DFI which was available to the researcher revealed that out of 185 accidents reported in 1999 only 16 (8.6 percent) of the total accidents was reported for WPI, while the KMLD reported 158 (64.7 percent) injuries for WPI in Kumasi Metro. In 2001, 40 (18.9 percent) out of 211 accidents recorded by DFI came from WPI, whiles the KMLD recorded 145 (65.6 percent) injuries for the WPI out of 221 injuries recorded.

In 2003, 26 (18.9 percent) out of 137 accidents were recorded by DFI for WPI whiles KMLD recorded 176 total injuries and out of this 115
(65.3 percent) were from the Wood processing industry. Thus, the extent of under reporting of industrial accidents in WPI only, ranges from 360 to 980 percent. If this is extended to other sectors of the economy, then, there is no doubt that the use of DFI statistics which has been used extensively in the past would not provide compelling evidence for adoption of OSH policy in Ghana.

It appears that the collection of workmen's compensation provided an incentive for the higher notification record of industrial accidents in the Wood Processing Industry at the KMLD (Ashanti). This may be explained by the key role the labour department plays in the collection of workmen's compensation for injured workers. There was no incentive to notify the DFI of accidents even though Act 328 of Factories Offices and Shop Act 1970 Section 10 stipulate the notification of accidents.

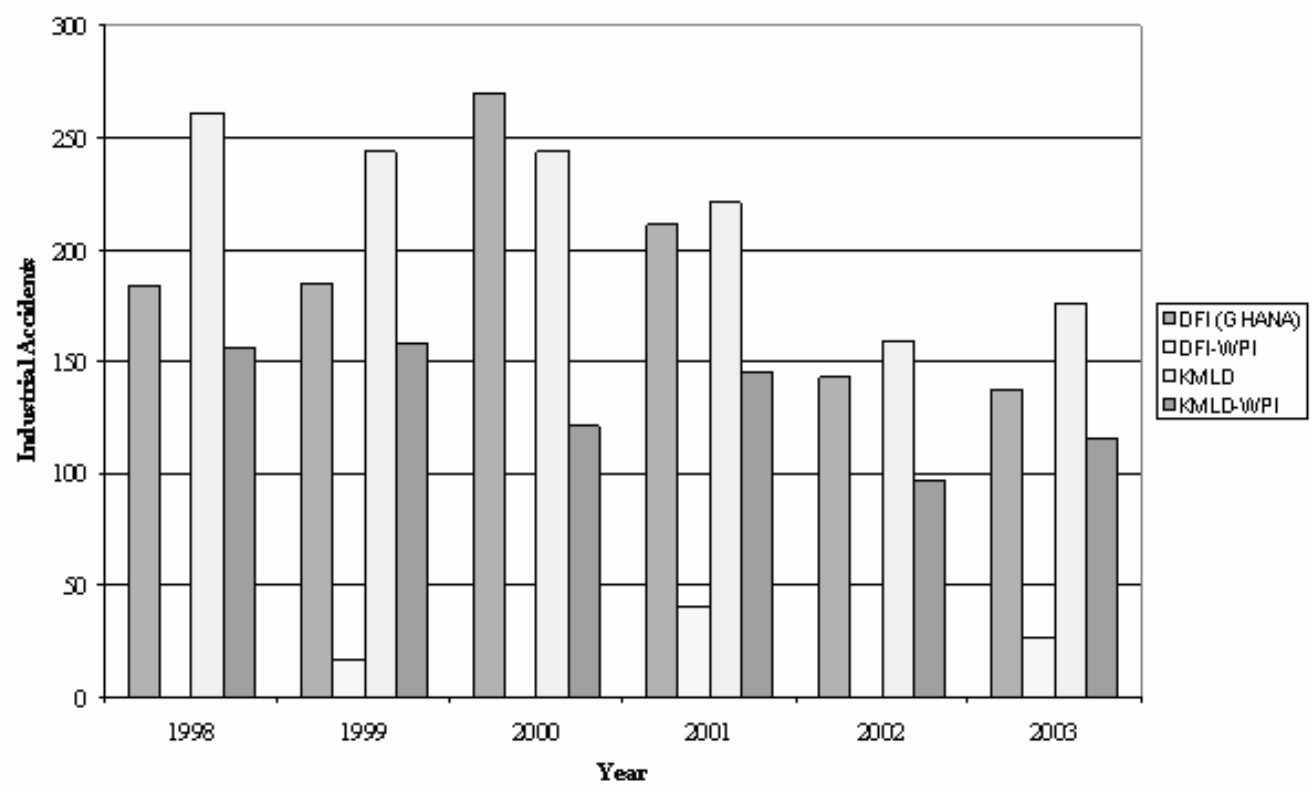

Figure 1: Industrial Accidents Records at DFI and KMLD 1998- 2003.

Sources: Department of Factories Inspectorate (DFI) Ghana Kumasi Metro Labour Department (KMLD) Ashanti Region

170 Journal of Science and Technology, Volume 27 no. 2, August, 2007 


\section{Enforcement of OSH Legislation in Wood Processing Industry}

Factories, Offices and Shop Act 1970 Act 328: The survey revealed that the DFI presently is faced with logistical, financial and staffing problems and that has made its responsibility of enforcing the Factories, Offices and Shop Act 1970 Act 328 ineffective. This is consistent with observations made by Boateng and Nimako, (2000) in their situational analysis of OSH in Ghana. Consequently, the inspectors perform only restrictive inspections (where factories with frequent accidents or a peculiar problem is visited frequently). The Factories, Offices and Shop Act, 1970 Act 328 sections 10 and 12 stipulate that employers are to report accidents and dangerous occurrence to the DFI. But according to an officer at DFI in Kumasi, most employers do not report such accidents, to enable them to investigate and put corrective measures in place to safe guard the safety and health of the workers in the facility in future. When investigations reveal violation of Factories, Offices and Shops Act 1970 , Act 328 by an employer, it usually takes a long time for the company to be prosecuted and also fines they are made to pay do not serve as a deterrent.

Workmen's Compensation: The survey revealed that apart from one large company (with $\mathrm{OSH}$ policy) and one medium sized company (without OSH policy) which rehabilitated severely injured workers, all the others did not provide any rehabilitation schemes because the Workmen's Compensation law made no provision for rehabilitation for workers who were severely incapacitated by occupational injury or disease.

Role of Timber and Wood Workers Union (TWU) According to the president of TWU, the union has recognized that the timber industry is as dangerous as the mining industry. Therefore in its biennial conference in 2005, they adopted OSH policy which has not yet been implemented. However the union ensures that OSH clauses are included in collective bargaining agreement for adequate enforcement of the law. Apart from one small company, all the other companies surveyed had a trade union representative. The trade union representative attended national and regional trade union meetings on how to protect and promote the rights and welfare of workers and disseminated information to their local members. According to the workers surveyed however, information was mainly with respect to remuneration instead of measures aimed at improving occupational safety and health in their work places. This is consistent with the observation made by other researchers (Clarke, 2004; WSF, 2004).

\section{CONCLUSION AND RECOMMENDATIONS}

In the WPIs surveyed the unsafe working environments and the workers vulnerability to occupational hazards and accident were found to be due to the following: inadequate OSH policy and procedures; low priority given to OSH agenda by Timber and Wood Workers Union; commitment by management to implement $\mathrm{OSH}$ policy where it existed and their consideration of payment of insurance premium as sufficient protection for workers. The restrictive inspections, education and enforcement carried out by under resourced $\mathrm{OSH}$ enforcement agencies and non-existent National OSH Policy gives an impression of the government's lack of commitment toward workers health and safety.

Workmen's compensation, which was, processed at the Labour Department accounts for the Department's higher statistics of industrial accidents than that of DFI. Therefore statistics at the Labour Departments may provide a true reflection of industrial accidents in Ghana and thus give compelling evidence for adoption of national OSH policy, than the under estimated DFI records which have been used by researchers and OSH advocates over the years.

Managers and supervisors should be trained in risk assessment to identify hazards. This will enable them put preventive measures in place to avoid or minimize occupational accidents. Man- 
agement should have OSH programmes where there will be compulsory workers participation; to bring their awareness of the hazards and the risks they are exposed to in the work place, and how to prevent them. Every employer in the WPI should provide incentives to workers who carry out their duties accident-free over a predetermined period as a means of inculcating safety consciousness in the workforce.

In order to achieve a high standard of OSH, there is the need for WPIs managements to shift organization of occupational health services from curative to preventive health services. Preemployment, periodic and exit medical examination if performed on all workers may safe guard the health of the workers and avoid future litigations.

To discourage WPIs managements from using insurance coverage as protection against occupational injuries the insurance companies should monitor and adjust the premiums to levels that will protect the health of WPIs workers and investments of management.

The government should provide adequate financial and logistical support to all enforcement agencies of OSH legislation to enable them effectively carry out their mandate. Finally, the ratification of ILO Occupational Safety and Health Convention C155, by Ghana government would go a long way to ensure a healthy, safe and satisfactory work environment and a healthy, active and productive worker who would contribute to poverty reduction and sustainable development.

\section{REFERENCES}

Acquah- Moses, E. E. K (2002). Lumber supply to the local market; From policy to practice chain saw lumber production a necessary evil? Troperbos International-Ghana Workshop. Proceedings 2. Wood industries training Center Akyawkrom, Ejisu, Kumasi, pp54.
Amedofu, G.K. (2002). "Hearing impairment among workers in gold mining in Ghana ". African Newsletter on Occupational Health and Safety . 12(3): 65-68.

Amedofu, G.K., and Asamoah-Boateng, C. (2003). "Industrial noise pollution and its effect on the hearing capabilities of Workers: A study from sawmills, printing presses and corn mills." Indian Journal of Clinical Practice West Africa Edition, 5(3):21.

Bean,.L.T., and Butcher, T.W,(2006). Wood dust exposure hazards. www.healthfully.org/eoh/ idl.html (Accessed: June, 2007).

Boateng, M., and Nimako, M. (2000). A situational analysis of Occupational Health and Safety in Ghana. Unpublished Draft Report Submitted to Ministry of Employment and Social Welfare, Accra, Ghana pp15, 18, 22.

Boateng, M. Y (1997). The impact of increased Deregulation and new Technology on the Employment and Occupational Safety and Health in the Food Drink and Tobacco (FDT) Industries in Ghana, Unpublished, Accra Ghana.

Clarke, E.E.K. (2004). "Multidisciplinary occupational health services" African Newsletter on Occupational Health and Safety, 14(1):3.

Ezeonu, F.C. (2004). "Occupational health hazards among cement industry workers"

African Newsletter on Occupational Health and Safety, 14:63-65.

Factories, Offices and Shop Act, (1970) Act 328. Ghana Publishing Corporation Accra, Tema, Ghana, GPC/A1384/7, 500/6/70. Ghana News Agency (Accra), Handbook on Occupational Health Launched, Sept 18, 2003, www.ghanaweb.com/GhanaHomepage/ NewsArchive. (Accessed: February, 2004)

Gardner, D., Cross, J.A.,. Fonleyn, P.N., Carlopio, J., and Shikdar, A. (1999). "Mechanical equipment injuries in small manufacturing Businesses" Safety Science 33: $1-12$.

172 Journal of Science and Technology, Volume 27 no. 2, August, 2007 
Ministry of Health, Occupational Health Unit (1998). Work place Health and Safety Hazards Survey. Report on the study of morbidity and working conditions of workers in the micro and small scale Enterprises in the Accra and Kumasi Metropolis Occupational Health Unit/MOH, Accra, Ghana pp17.

Ministry of Health/Ghana Health Services (2002). A hand book of occupational Health, GHS/ MOH , Occupational and Environmental Health Unit, Accra, Ghana pp55.

Matooane, B.M.(1997). "The wood working industry in Lesotho" African News letter on Occupational Health and Safety, 7(2):46-47.

McCann,.M. and Babin, A. (2007). Wood working hazards. www.woodworkersclub.com/ woodhazards.htm.(Accessed: June, 2007)
Nui, S.(2000). "Occupational Safety and health in the health care sector" African News letter on Occupational Health and Safety, 10 (3):58.

Odhiambo, C.B. (2003). "Poverty is diminishing health and safety" African Newsletter on Occupational Health and Safety, 13:65-66

WHO(1994). Global strategy occupational health for all www.who.org. (Accessed: March, 2001)

Workmen's Compensation Law, 1987 PNDCL 187, GPC, Printing division A\&O Presses

GPC/A475/2,600/10/SS. Worlds Social Forum (2004) www.labourfile.org. Mumbai, India (Accessed: March, 2005) 